\title{
CASE OF CONVULSIVE MOVEMENTS OF RIGHT ARM, HYSTERICAL IN NATURE
}

\author{
By M. D. Bloomfield, M.D.
}

Case of convulsive movements of right arm, hysterical in nature in a patient whose history of onset of the seizure and objective findings, such as endomyocarditis and arterio-sclerotic vessels, might easily throw one off the right track in diagnosis, especially since no stigmata of hysteria are present. So far these movements have lasted five years and despite every effort at treatment by some of our most eminent men, these movements are progressing for the worst. As soon as the patient's mind is directed from himself the movements cease.

\section{A CASE OF PREFRONTAL TUMOR, WITH EXHIBITION OF THE BRAIN}

\section{By C. W. Burr, M.D.}

Dr. Burr exhibited the brain from a patient with a tumor of the prefrontal lobe. He said that the interesting points in the case werethe suddenness of onset, the shortness of the course and fewness of symptoms. The history is as follows:

A woman, 39 years old, who had had slight headache at times for two years, but no other symptoms, was picked up unconscious in the street. It was not known whether she had had an epileptiform convulsion or not. She remained in bed for several weeks suffering from severe, diffuse, continuous headache. Her eyesight rapidly failed. She then came to the hospital.

Physical examination. She was somewhat du1l in thouglit but explained this by saying "that her head hurt her so much that she couldn't think." She answered all questions intelligently and, indeed, the only mental symptom present was slight slowness of thought Gait and station were good but she stated that after standing or walking for a time she became dizzy. There was no paralysis of the arms or legs but the left side of the mouth drooped a little and on voluntary movement of the face the left side lagged somewhat. No ataxia or tremor. The knee jerks were slightly increased but not spastic. There was no ankle-clonus and no Babinski jerk. She could not see to read but could distinguish people. The irides reacted to light and with accommodation and convergence. There was no oculo-motor palsy. Both discs were choked and there were small retinal hemorrhages.

Nine weeks after the attack of unconsciousness she was found dead in bed. At necropsy there was found an endothelioma in the right prefrontal lobe about as large as a hen's egg, imbedding itself within the brain but having pushed the cortex ahead of it so that it lay in a socket formed of brain tissue.

\section{A CASE OF BRAIN TUMOR}

By J. Hendrie Lloyd, M.D.

Dr. James Hendrie Lloyd showed a brain with a tumor growing in the motor area of the right cerebrum. The patient was a very old 
woman, a Polish emigrant, unable to speak English, who had died recently in the Philadelphia Hospital. The true nature of the lesion had been overlooked and the case had been regarded as one of ordinary hemiplegia. This was doubtless due to the difficulty of obtaining a history and of interpreting symptoms, and to the close resemblance which the case bore to ordinary cerebral softening in the aged.

The tumor was located exactly in the fissure of Rolando at about its middle third. The arm centers must have been first involved. The ascending frontal convolution was compressed in front, and the ascending parietal convolution was compressed behind the growth. The tumor measured about five centimeters in diameter and was flattened by contact with the skull. It was entirely meningeal, compressing the brain substance and could easily have been removed by surgical operation. From its location it may have caused interesting sensory as well as motor symptoms, but unfortunately these had been overlooked. The hemiplegia was of the spastic type, with greatly exaggerted reflexes.

Dr. Lloyd called attention to the ease with which brain tumors may be overlooked or confused with other lesions, especially cerebral hemorrhage and softening. The present case had been under the care of at least three visiting chiefs at Blockley, but its real nature had not been suspected.

\section{A CASE OF PARTIAL CROSSED HEMIASYNERGIA}

\section{By Tom A. Williams, M.D., of Washington, D. C.}

The possibility of its aiding in the future solution of some hitherto unsolved problem regarding the course of impulses coming to and leading from the cerebellım had induced Dr. Williams to present this remarkable case of cerebellar hemi-asynergia in which the opposite side of the face is also implicated.

It is unfortunately, however, impossible as yet to infer legitimately regarding the actual lesion; for the patient is in all probability syphilitic and both cerebellar lobes may be implicated.

Dr. Williams was obliged to Dr. Elliot of the Emergency Hospital, Washington, for the privilege of reporting the case.

It is that of a man aged 3I years who six months ago began to feel weak and dizzy and had severe pains in the loins and occiput which kept him awake at night. For three weeks he worked and then went to bed for two months by medical orders. About two months ago he noticed that the left hand was clumsy and that silly thoughts occtipied his mind while he was perambulating the streets without occupation. These were chiefly about money. $\mathrm{He}$ also had noticed some difficulty about swallowing.

Physical Examination.-On the facial movements being tested they are seen to be accompanied on the right side by a very decided irregular, coarse tremor of the cheek, jaw, lips and tongue, the left side remaining in equilibrium except in so far as it is shaken by the communicated movements of the right side. The eyes are also unsteady when turned to the right. On protrusion of the tongue, its right side is agitated by a similar tremor which almost ceases in about ten seconds, after which interval there is also more control over the facial trembling.

In the left arm there is slight asthenia, considerable impairment of 